Journal of Engineering and Applied Sciences 15 (5): 1190-1204, 2020

ISSN: $1816-949 \mathrm{X}$

(C) Medwell Journals, 2020

\title{
Driving Strategic Leadership and Organizational Learning Culture towards Organizational Sustainability
}

\author{
${ }^{1}$ Mohsin Naser A.N. Alharthi, ${ }^{2}$ Gamal S.A. Khalifa, ${ }^{1}$ Ali Ameen, \\ ${ }^{1}$ Ahmed Hamoud Al-Shibamid and ${ }^{1}$ Osama Issac \\ ${ }^{1}$ Faculty of Business and Accountancy, \\ ${ }^{2}$ Faculty of Hospitality and Tourism, \\ Lincoln University College (LUC), Selangor, Malaysia
}

\begin{abstract}
Based on leadership theory and social exchange theory, the study investigated the role of Strategic Leadership (SL) and Organizational Learning Culture (OLC) on Organizational Sustain ability (OS) among employees in the General Directorate of Residency and Foreigners Affairs (GDRFA), UAE. The current study adopted SEM to test the study's hypothesis. A sample of 372 employees in the GDRFA was selected randomly. In this representative sample, a survey was carried out to find out the extent of SL and OLC influence on OS. All the study's hypothesis were supported. SL is significantly predicting OS, SL is significantly predicting OLC and OLC is significantly predicting OS. As well as, OLC is significantly mediates the relationship between SL and OS. The proposed model explained $64.7 \%$ of the variance in OS. Finally, theoretical and managerial implications were discussed.
\end{abstract}

Key words: Strategic leadership, organizational learning, organizational sustainability, UAE, significantly, residency

\section{INTRODUCTION}

Sustainability has approached as a protuberant topic in corporate boardrooms, academia and organizational stability. Nidumolu et al. (2009) argued that sustainable sustainability is the only way available for enterprises growth, decreasing production costs and generating additional revenues from novel offerings or business expansion. Despite the core meaning of sustainability, organizational understanding is how to achieve it remains elusive. There are several concepts are around regarding sustainability defines underpinning by divergent values and believes. It is commonly has been considered as a crucial goal for organization which have arisen regarding vroles play in maintaining sustainability (Paulraj, 2011; Thomas and Lamm, 2012).

For instance, Steurer and Hametner, (2013) have identified long-term competitiveness and organizational economic impacts are key issues of organizational sustainability. Organizational sustainability represents an on-going process rather than a state of perfection. It is like a plant, it will grow and prosper if watered and cared for but wither quickly if it is not (Benn et al., 2014). Furthermore, organizations are like a body, if one part is ill the rest will not function like it should. If too many parts fail at once or in quick succession, the body dies. So, keeping an organization sustainable requires a constant effort and unity of purpose focused on one overarching mission (Moizer and Tracey, 2010). Every staff member and manager must see both the forest and the trees or the organization becomes entangled in the underbrush. So, organizational sustainability is most important for the research to allocate the organization stability with the productivity, employability, security and overall satisfaction (Alkathiri et al., 2018; Mohamed et al., 2018; Alharthi et al., 2019; Smith, 2012).

Accordingly, the strategic leadership has been stimulating in the corporate and industrial organization for achieving target goal by utilizing the strategic plan of the future activities (Alkathiri et al., 2018; Vera and Crossan, 2004). Many researchers ask what the competencies are that strategic leaders should possess, apart from the abilities of information retrieval, developing shared visions, team working, strategic planning, driving to excel and management administration and leadership improvement which are necessary for an effective leader (Boal and Hooijberg, 2000; Finkelstein et al., 2009). In this study strategic leadership has articulated as utilize the future plan maker and imply the strategies for a gaol to get success. It plays as an independent form to ensure the relationship with organizational learning culture directly. To the prior knowledge of the researchers this relationship means a good implication for the organization as it previously discussed in little consideration in the literature.

In addition, organizational learning culture has been practiced as an important key element of the organization (Abd-Elaziz et al., 2015; Abou-Shouk and Khalifa, 2017; Agwa et al., 2018; Badran and Khalifa, 2013; Khalefa, 2015; Khalifa and Fawzy, 2017; Khalifa and Hewedi, 2016; Khalifa and Mewad, 2017; Mohamed et al., 2018, 2019; Mohamud et al., 2017; Nusari et al., 2018; 
Alharthi et al., 2019). Joo and Park (2010) have emphasizes the importance of organizational learning culture for organizational success. It as a process through which managers try to increase organizational member's capabilities in order to better understand and manage the organization and its environment' (Jones et al., 2014). For instance, Watkins and Marsick developed an analytical framework of the learning organization which was used in the study by Egan as a substitute for learning culture (Hung et al., 2010). The research addresses organizational learning culture which is proposed and defined as a set of norms and values about the functioning of an organization. It is a combination of different culture types within the competing values framework (Joo and Shim, 2010). It is defined as the organization's skilled of creating, acquiring and transferring knowledge and at modifying its behaviour to reflect new knowledge and insights (Garvin, 1993). Therefore, learning practice and its culture to continuity by sharing knowledge with others is commonly essential for the knowledge building within the organization. Thus, organizational leaning culture explains in thus study as mediating place of between strategic leadership and organizational learning culture. Strategic leadership indirectly influence on organizational sustainability for corporate basis of planning implementation and clarify the place for learning in terms of healthy productivity.

\section{Literature review \\ Strategic leadership: Past studies advocate that strategic} leaders play a critical role in shaping their subordinate's motivation to accomplish set tasks (Ribiere and Sitar, 2003). Strategic ability enables organizations to flexibly respond to complex, global and dynamic environments (Van Houten and Jacobs, 2005). Yet achieving strategic ability is challenging in part because of inherent contradictions. Building capabilities for organizational renewal requires on the one hand of formal strategic planning laying the groundwork for competitive advantage (Daily et al., 2002). In addition, strategic leadership commitments allocate resources to build core competencies and provide a base from which organizations can learn and adapt (Rowe, 2001). On the other hand, demands strategic flexibility, quick and innovative responses to the dynamic competitive landscape. Such changes help organizations cope with technological discontinuities to anticipate market trends and disruptions (Koons, 2009). Strategic leaders are made appropriate investments for future viability while maintaining an appropriate level of financial stability in the present situation. It is common that they are not only increasing the financial stability but also increasing the total plan for establishment (Elenkov et al., 2005). Under pure strategic leadership there is a much wider range of wealth creation possible that may influence of a managerial leader. Unfortunately, most of the administrative organization, specially, government rules oriented organization implicitly and explicitly train their followers to be general leader (Alsaadi et al., 2019; Alharthi and Khalifa, 2019). This is not bad but when such leadership does not allow visionary and strategic leadership to flourish it damaging the organization for long-time (Leithwood et al., 2004). The direct influence of strategic leadership to organizational learning culture ensure the leaders can cooperate with their capabilities and knowledge or combining both of approaches of getting future success by achieving goal. Consequently, strategic leadership indirectly relates with the organizational sustainability in order to ensure the sustainable context within the organization. Little studies have been researched for the direct and indirect relationship which fulfil by this contribution. Consequently, the following hypothesis is proposed:

- $\mathrm{H}_{1}$ : SL has a positive effect on OS

- $\mathrm{H}_{2}$ : $\mathrm{SL}$ has a positive effect on OLC

Organizational learning culture: Skerlavaj et al. (2010) showed that an organization's learning culture promotes sustainability. It encourages knowledge sharing among the colleagues and supports the new ideas implementation, utilization of knowledge for commercialization (Joo, 2010). Thus, it needs to be supported by an organization capability to explore and exploit the knowledge (Joo and Shim, 2010; Sanz-Valle et al., 2011; Templeton et al., 2002). Therefore, organization learning culture is inferred that its absorptive capacity will result in enhanced outbound open sustainable outcomes (Froehlich et al., 2014). The basic idea behind this research is that organizational learning culture is very important when trying to improve organizational sustainability. In addition, it is a complex process that refers to the development of new knowledge and has the potential to change behaviour (Naqshbandi and Kamel, 2017). Organizations have developed a strong learning culture are good at creating, acquiring and transferring knowledge as well as at modifying behaviour to reflect new knowledge and insight (Garvin, 1993). Hence, organizations stressing organizational learning culture must first acquire information, interpret it to fully understand its meaning and transform it into knowledge. Senge (2006) defined organizational learning as a continuous testing of experience and its transformation into knowledge available to whole organization and relevant to their mission. Cook and Yanow (1993) saw it as a combination of four processes: information acquisition, information distribution, information interpretation and organizational memory. However in this study organizational learning culture implement the relation with organizational 
sustainability in order to focus on sharing the learning culture in term of build-up sustainability. As discussed in the literature review, we used Skerlavaj et al. (2007) understanding of organizational learning culture that relates the process of organizational learning to the competing values fram ework of organizational culture. In this regard, organizational learning culture plays in essential role in relationship with organizational sustainability directly. It placed as mediating between strategic leadership and organizational sustainability in order to make the consistency of the organization. Hence, it is hypothesized as follows:

- $\mathrm{H}_{3}$ : OLC influences positively on OS

- $\mathrm{H}_{4}$ : OLC mediates the relationship between $\mathrm{SL}$ and OS

Organizational sustainability: The literature regarding organizational sustainability of business focuses primarily on rationales for adopting sustainability strategies and operational practices in support of that goal (Mohrman and Worley, 2010). Organizational sustainability has a normative underpinning that considers an organization or a community sustainable when it contributes to a more sustainable world as can be understood with our current knowledge and understanding of what sustainability might entail (Florea et al., 2013). In other words, a sustainable organization does not refer to an organization that succeeds in keeping itself going by maintaining for instance, profitability but rather to one that given what we know today, successfully balances people, prosperity (Linnenluecke and Griffiths, 2010). Organizational sustainability poses particular problems for organization (Foster and Bradach, 2005). In order to explain the potential relationship between the learning culture of an organization and the pursuit of organizational sustainability principles, researcher first review and explore the concept of sustainability (Eccles et al., 2014). It is argued that although, this concept has received much attention in recent organizational and management studies there is still little insight into how the adoption of sustainability practices can be achieved inside organizations (Wikstrom, 2010). Furthermore, the concepts of organizational sustainability and organizational learning culture share similarities across various dimensions and provide a conceptual foundation for a more thorough analysis on sustainability-related culture change. Several scholars maintain that there are insufficient as they are only superficial and not conducive to the formation of sustainable organizations and industries (Hart and Milstein, 1999; Senge and Carstedt, 2001). They argued that in order to fully respond to environmental and social challenges, organizations will have to undergo significant cultural change and transformation (Dingwerth and
Pattberg, 2009; Presley et al., 2007). On top of that organizational sustainability actually makes affordable situation as part of create stability of its future palace to the market. The complimentary situational broad place of its standard possibility in the market builds up organizational power of productivity. In this study, organizational sustainability plays as the dependent place of resolve learning culture and provide organizational strategies for future plan.

\section{MATERIALS AND METHODS}

Overview of the proposed research model: For this study, the hypothesized variables and their relationships in the model have been derived from the available literature of the models and theories that have been prescribed in the literature mentioned above. The proposed model can be seen in Fig. 1. While examining the proposed model, it can be seen that SL and OLC predicts OS. These relationships are derived from (Gauhara, 2014) for SL for OLC and for OS. The proposed extended model examines the relationship between SL, OLC as antecedent variables that explain OS as an output variable among employees from GDRFA in the United Arab Emirates. The proposed model has four hypothesis to test.

Development of Instrument: A 48-item questionnaire was developed for this study. Because the respondents were Arab-speaking, it was imperative that it be accurately translated from English to Arabic. Back translation was used in this study, a procedure commonly used in cross-cultural surveys to test the accuracy of the translation (Brislin, 1970).

This study applied multi-item Likert scales which have been widely used in the questionnaire-based perception studies (Lee et al., 2009). Unlike actual usage which is measured using a 5-point ranking scale, other variables are subjectively measured using the 5-point Likert scale with 5 being 'Strongly agree' and 1 being 'Strongly disagree'. For this study, a pre-testing was conducted with 50 employees from GDRFA, UAE to resolve any ambiguity associated with wording or measurement. Then the items were pilot-tested to examine their internal consistency. Out of 500 surveys administered GDRFA, 372 employees were returned with complete and valid data. In the final questionnaire, all items had acceptable reliability as the individual Cronbach's alpha coefficients of the constructs which ranged from 0.874-0.919 were all greater than the recommended value of 0.7 (Nunnally and Bernstein, 1994).

Data collection: Data collection was conducted using a self-administered paper questionnaire which was 


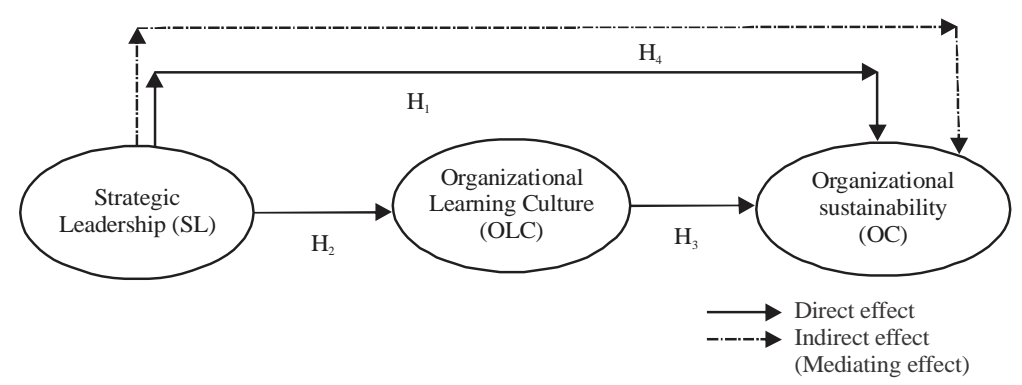

Fig. 1: Proposed research model

delivered 'in-person' from October, 2017 until August, 2018 to GDRFA, UAE. The researcher investigated 11 GDRFA units out of 15 units in UAE. The researcher distributed 500 questioners to the UAE GDRFA's employees; the valid questionnaires received by the researcher are 372 questionnaires by responding rate is $74.4 \%$. The final sample size was considered as adequate (Krejcie and Morgan, 1970; Tabachnick and Fidell, 2012). The $74.4 \%$ response rate is considered very good (Cable and DeRue, 2002) and above average (Baruch and Holtom, 2008) by comparison with other studies found in the relevant literature. A total of 15 questionnaires were deleted of which 10 cases were removed due to missing data for more than $15 \%$ of the questions and 5 cases involving straight lining.

\section{RESULTS AND DISCUSSION}

Descriptive analysis: The responding sample $(n=372)$ consisted of $58.1 \%$ male and $41.9 \%$ female employees which refers that the majority of the GDRFA's employees are male. The majority ages of the participants range from 30-39 years old. As Table 1 presents that $41.4 \%$ of the respondents were aged $30-39$ years, $28 \%$ of employees are $<30$ years. The employee's educational level is limited by below secondary school, secondary school, Bachelor, Master and $\mathrm{PhD}(7,23.1,58.6,6.5$ and $4.8 \%$, respectively). Surprisingly, the job tenure of the workers reflects that the period that employees stay at their work are moderate. For instance, more than $66.1 \%$ of those employees stay in their work $<15$ years. Employees nationalities show that $98.4 \%$ of them are local, see Table 1.

Measurement model assessment: This study employed Structural Equation Modeling-Variance Based (SEM-VB) through Partial Least Squares (PLS) method to analyze the research model using the software of Smart PLS 3.0 (Ringle et al., 2015). After the descriptive analysis, this study follows the two-stage analytical technique recommended by (Anderson and Gerbing, 1988; Hair et al., 2017) starts with the measurement model
Table 1:Summary of demographic profile of respondents

\begin{tabular}{lrc}
\hline Variables & Frequency & Valid percentage \\
\hline Gender & 216 & \\
Male & 156 & 58.10 \\
Female & & 41.90 \\
Age & 104 & \\
$<30$ & 154 & 28.00 \\
$30-39$ & 87 & 41.40 \\
$40-49$ & 23 & 23.40 \\
$50-59$ & 4 & 6.20 \\
60 above & & 1.10 \\
Education & 26 & \\
Below secondary school & 86 & 7.00 \\
Secondary school & 218 & 23.10 \\
Bachelor & 24 & 58.60 \\
MSc & 18 & 6.50 \\
PhD & & 4.80 \\
Tenure & 77 & \\
$<5$ (years) & 76 & 20.70 \\
5-10 & 93 & 20.40 \\
11-15 & 71 & 25.00 \\
16-20 & 55 & 19.10 \\
More than 20 & & 14.80 \\
Nationality & 366 & \\
UAE & 6 & 98.40 \\
Foreigner & & 1.60 \\
\hline
\end{tabular}

assessment (validity and reliability) followed by the structural model assessment (testing the hypothesized relationships). Schumacker and Lomax (2004) and Hair et al. (2010) indicate that the two steps assessment procedure which includes measurement model and structural model has an advantage over the one step assessment procedure. According to Hair et al. (2017) measurement model specifies how each construct is measured while structural model specifies how the variables are related to each other in the structural model. The main reasons for choosing PLS as a statistical method for this study that for both measurement and structural model PLS offer simultaneous analysis which leads to more accurate estimates (Barclay et al., 1995).

The assessment of measurement model was done through construct reliability as well as validity (including convergent and discriminant validity). For construct reliability, this study tested the individual Cronbach's alpha coefficients to measure the reliability of each of the core variables in the measurement model. The results 
J. Eng. Applied Sci., 15 (5): 1190-1204, 2020

Table 2: Mean, standard deviation, loading, Cronbach's alpha, CR and AVE

\begin{tabular}{|c|c|c|c|c|c|c|}
\hline Constructs/Item & Loading $(>0.5)$ & $\mathrm{M}$ & $\mathrm{SD}$ & $\alpha(>0.7)$ & $\mathrm{CR}(>0.7)$ & $\mathrm{AVE}(>0.5)$ \\
\hline Organizational Culture Practices (OCP) & & & & 0.894 & 0.934 & 0.825 \\
\hline OCP1 & 0.918 & - & - & - & - & - \\
\hline OCP2 & 0.906 & - & - & - & - & - \\
\hline OCP3 & 0.902 & - & - & - & - & - \\
\hline Human Capital Practices (HCP) & & & & 0.874 & 0.922 & 0.798 \\
\hline HCP1 & 0.880 & - & - & - & - & - \\
\hline $\mathrm{HCP} 2$ & 0.893 & & & - & - & - \\
\hline $\mathrm{HCP} 3$ & 0.907 & - & - & - & - & - \\
\hline Strategic Vision Practices (SVP) & & & & 0.907 & 0.941 & 0.843 \\
\hline SVP1 & 0.915 & - & - & - & - & - \\
\hline SVP2 & 0.920 & - & - & - & - & - \\
\hline SVP3 & 0.919 & - & - & - & - & - \\
\hline Organizational Control Practices (OCON) & & & & 0.893 & 0.934 & 0.824 \\
\hline OCON1 & 0.919 & - & - & - & - & - \\
\hline $\mathrm{OCON} 2$ & 0.916 & & & - & - & - \\
\hline OCON3 & 0.888 & - & - & - & - & - \\
\hline Organizational Learning culture (OLC) & & & & 0.919 & 0.934 & 0.639 \\
\hline OLC1 & 0.733 & - & - & - & - & - \\
\hline $\mathrm{OLC} 2$ & 0.791 & - & - & - & - & - \\
\hline $\mathrm{OLC} 3$ & 0.834 & - & - & - & - & - \\
\hline $\mathrm{OLC} 4$ & 0.846 & & & - & - & - \\
\hline OLC5 & 0.831 & - & - & - & - & - \\
\hline OLC6 & 0.784 & - & - & - & - & - \\
\hline OLC7 & 0.798 & - & - & - & - & - \\
\hline OLC8 & 0.771 & - & - & - & - & - \\
\hline Organizational sustainability (OS) & & & & 0.959 & 0.963 & 0.520 \\
\hline ADMIN1 & 0.889 & - & - & - & - & - \\
\hline ADMIN2 & 0.895 & - & - & - & - & - \\
\hline ADMIN3 & 0.916 & - & - & - & - & - \\
\hline ADMIN4 & 0.886 & - & - & - & - & - \\
\hline ADMIN5 & 0.864 & - & - & - & - & - \\
\hline ADMIN6 & 0.816 & - & - & - & - & - \\
\hline $\mathrm{ECO} 1$ & 0.856 & - & - & - & - & - \\
\hline $\mathrm{ECO} 2$ & 0.845 & - & - & - & - & - \\
\hline $\mathrm{ECO} 3$ & 0.890 & - & - & - & - & - \\
\hline $\mathrm{ECO} 4$ & 0.855 & - & - & - & - & - \\
\hline $\mathrm{ECO} 5$ & 0.786 & - & - & - & - & - \\
\hline ECO6 & 0.804 & - & - & - & - & - \\
\hline ENV1 & 0.844 & - & - & - & - & - \\
\hline ENV2 & 0.850 & - & - & - & - & - \\
\hline ENV3 & 0.897 & - & - & - & - & - \\
\hline ENV4 & 0.923 & - & - & - & - & - \\
\hline ENV5 & 0.805 & - & - & - & - & - \\
\hline ENV6 & 0.875 & - & - & - & - & - \\
\hline Social1 & 0.771 & - & - & - & - & - \\
\hline Social2 & 0.788 & - & - & - & - & - \\
\hline Social3 & 0.776 & - & - & - & - & - \\
\hline Social4 & 0.817 & - & - & - & - & - \\
\hline Social5 & 0.749 & - & - & - & - & - \\
\hline$x_{1}$ & 0.695 & - & - & - & - & - \\
\hline
\end{tabular}

indicate that all the individual Cronbach's alpha coefficients ranging from $0.874-0.959$ were higher than the suggested value of 0.7 (Kannan and Tan, 2005; Nunnally and Bernstein, 1994). Additionally, for testing construct reliability all the Composite Reliability (CR) values ranging from $0.922-0.963$ were higher than 0.7 (Werts et al., 1974; Kline, 2010; Gefen et al., 2000) which adequately indicates that construct reliability is fulfilled as shown in Table 2. Therefore, the achieved Cronbach's alpha and CR for all constructs were considered to be sufficiently error-free.
Factor loading was used to test indicator reliability. High loadings on a construct indicate that the associated indicators seem to have much in common which is captured by the construct (Hair et al., 2017). Factor loadings $>0.50$ were considered to be very significant (Hair et al., 2010). The loadings for all items exceeded the recommended value of 0.5 as shown in Table 2 . The loading for all items in the model has therefore fulfilled all the requirements.

For testing convergent validity (the extent to which a measure correlates positively with alternative measures 
of the same construct) this study used the Average Variance Extracted (AVE) and it indicated that all AVE values were higher than the suggested value of 0.50 (Hair et al., 2010) ranging from 0.520-0.843. The convergent validity for all constructs has been successfully fulfilled and adequate convergent validity exhibited as Table 2 shows.

The discriminant validity (the degree to which items differentiate among constructs or measure distinct concepts) of the measurement model was checked using three criteria, namely cross-loadings, Fornell-Larcker and the Heterotrait-Monotrait ratio (HTMT). According to Hair et al. (2017) the cross-loadings are typically the first approach to assess discriminant validity of the indicators. As shown in Table 3 the cross loading criterion fulfills the requirements because the indicators outer loadings on a construct were higher than all its cross-loadings with other constructs (bold values).

The results of discriminant validity by using the Fornell-Larcker criterion is shown in Table 4 where the square root of the AVEs on the diagonals as represented by the bolded values are higher than the correlations between constructs (corresponding row and column values). This indicates that the constructs are strongly related to their respective indicators compared to other constructs of the model(Fornell and Larcker, 1981; Chin, $1998 \mathrm{a}, \mathrm{b})$ thus, suggesting a good discriminant validity (Hair et al., 2017). In addition, the correlation between exogenous constructs is $<0.85$ (Awang, 2014). Hence, the discriminant validity of all constructs is fulfilled.

There has been some criticism of the Fornell-Larcker criterion, Henseler et al. (2015) mentioned that it does not accurately reveal the lack of discriminant validity in common research situations. They have proposed an alternative technique which is the Heterotrait-Monotrait ratio (HTMT) of correlations based on the multitrait-multimethod matrix. This study assesses discriminant validity through HTMT. While the discriminant validity has a problem when the HTMTvalue is greater than $\mathrm{HTMT}_{0.90}$ value of 0.90 (Gold et al., 2001), or the $\mathrm{HTMT}_{0.85}$ value of 0.85 (Kline, 2010) all values as Table 5 shows were lower than the recommended value of 0.85 indicating that discriminant validity has been ascertained.

Structural model assessment: Hair et al. (2017) suggested assessing the structural model by looking at the beta $(\beta), \mathrm{R}^{2}$ and the corresponding t-values via. a bootstrapping procedure with a resample of 5,000 . Moreover, they recommend reporting the effect sizes $\left(\mathrm{f}^{2}\right)$ as well as the predictive relevance $\left(\mathrm{Q}^{2}\right)$. As (Sullivan and Feinn, 2012) argue that the p-value determine whether the effect exists but it does not reveal the size of the effect (Fig. 2).

Hypothesis tests: The structural model assessment as shown in Fig. 2 and Table 6 provides the indication of the
Table 3: Results of discriminant validity by the cross loading

\begin{tabular}{|c|c|c|c|}
\hline Variables & OLC & OS & SL \\
\hline ADMIN1 & 0.594 & 0.889 & 0.626 \\
\hline ADMIN2 & 0.636 & 0.895 & 0.643 \\
\hline ADMIN3 & 0.574 & 0.916 & 0.568 \\
\hline ADMIN4 & 0.603 & 0.886 & 0.556 \\
\hline ADMIN5 & 0.536 & 0.864 & 0.598 \\
\hline ADMIN6 & 0.650 & 0.816 & 0.622 \\
\hline ECO1 & 0.512 & 0.856 & 0.510 \\
\hline $\mathrm{ECO} 2$ & 0.494 & 0.845 & 0.410 \\
\hline $\mathrm{ECO} 3$ & 0.566 & 0.890 & 0.503 \\
\hline $\mathrm{ECO} 4$ & 0.568 & 0.855 & 0.468 \\
\hline $\mathrm{ECO} 5$ & 0.616 & 0.786 & 0.588 \\
\hline ECO6 & 0.607 & 0.804 & 0.578 \\
\hline ENV1 & 0.559 & 0.844 & 0.474 \\
\hline ENV2 & 0.558 & 0.850 & 0.502 \\
\hline ENV3 & 0.519 & 0.897 & 0.492 \\
\hline ENV4 & 0.567 & 0.923 & 0.503 \\
\hline ENV5 & 0.546 & 0.805 & 0.519 \\
\hline ENV6 & 0.555 & 0.875 & 0.505 \\
\hline Social1 & 0.561 & 0.771 & 0.503 \\
\hline Social2 & 0.563 & 0.788 & 0.534 \\
\hline Social3 & 0.533 & 0.776 & 0.476 \\
\hline Social4 & 0.531 & 0.817 & 0.524 \\
\hline Social5 & 0.463 & 0.749 & 0.482 \\
\hline Social6 & 0.395 & 0.695 & 0.388 \\
\hline HCP1 & 0.650 & 0.631 & 0.880 \\
\hline $\mathrm{HCP} 2$ & 0.602 & 0.537 & 0.893 \\
\hline HCP3 & 0.561 & 0.502 & 0.907 \\
\hline OCON1 & 0.473 & 0.565 & 0.919 \\
\hline OCON2 & 0.509 & 0.585 & 0.916 \\
\hline OCON3 & 0.591 & 0.554 & 0.888 \\
\hline OCP1 & 0.491 & 0.461 & 0.918 \\
\hline OCP2 & 0.533 & 0.478 & 0.906 \\
\hline OCP3 & 0.571 & 0.491 & 0.902 \\
\hline SVP1 & 0.602 & 0.544 & 0.915 \\
\hline SVP2 & 0.592 & 0.635 & 0.920 \\
\hline SVP3 & 0.618 & 0.643 & 0.919 \\
\hline OLC1 & 0.733 & 0.566 & 0.607 \\
\hline OLC2 & 0.793 & 0.609 & 0.588 \\
\hline OLC3 & 0.832 & 0.645 & 0.590 \\
\hline OLCA & 0.845 & 0.701 & 0.602 \\
\hline OLC5 & 0.829 & 0.643 & 0.619 \\
\hline OLC6 & 0.786 & 0.592 & 0.611 \\
\hline OLC7 & 0.796 & 0.600 & 0.568 \\
\hline OLC8 & 0.774 & 0.560 & 0.582 \\
\hline
\end{tabular}

SL: Strategic Leadership, OLC: Organizational Learning Culture, OS: Organizational Sustainability

hypothesis tests with 3 out of the 3 hypothesis are supported. SL, significantly predict $\mathrm{OS}$. Hence, $\mathrm{H}_{1}$ is accepted with $(\beta=0.345, \tau=6.409, \mathrm{p}<0.001$. SL, significantly predict OLC. Hence, $\mathrm{H}_{2}$ is accepted with $(\beta=0.745, \tau=26.199, \mathrm{p}<0.001$. OLC, significantly predict OS. Hence, $\mathrm{H}_{3}$ is accepted with $(\beta=-0.414$, $\tau=11.236, p<0.001$. SL and OLC are explaining $64.7 \%$ of the variance in OS. The $\mathrm{R}^{2}$ values achieved an acceptable level of explanatory power as recommended by Cohen (1988) and Chin (1998a, b) indicating a substantial model.

This study also assessed effect sizes $\left(\mathrm{f}^{2}\right)$. Effect size $\mathrm{f}^{2}$ determines whether an exogenous latent construct has a substantial, moderate or weak impact on an endogenous latent construct (Gefen and Rigdon, 2011). Hair et al. (2017) recommend to test the change in the $\mathrm{R}^{2}$ value. Cohen (1988) suggested a guideline measure the 


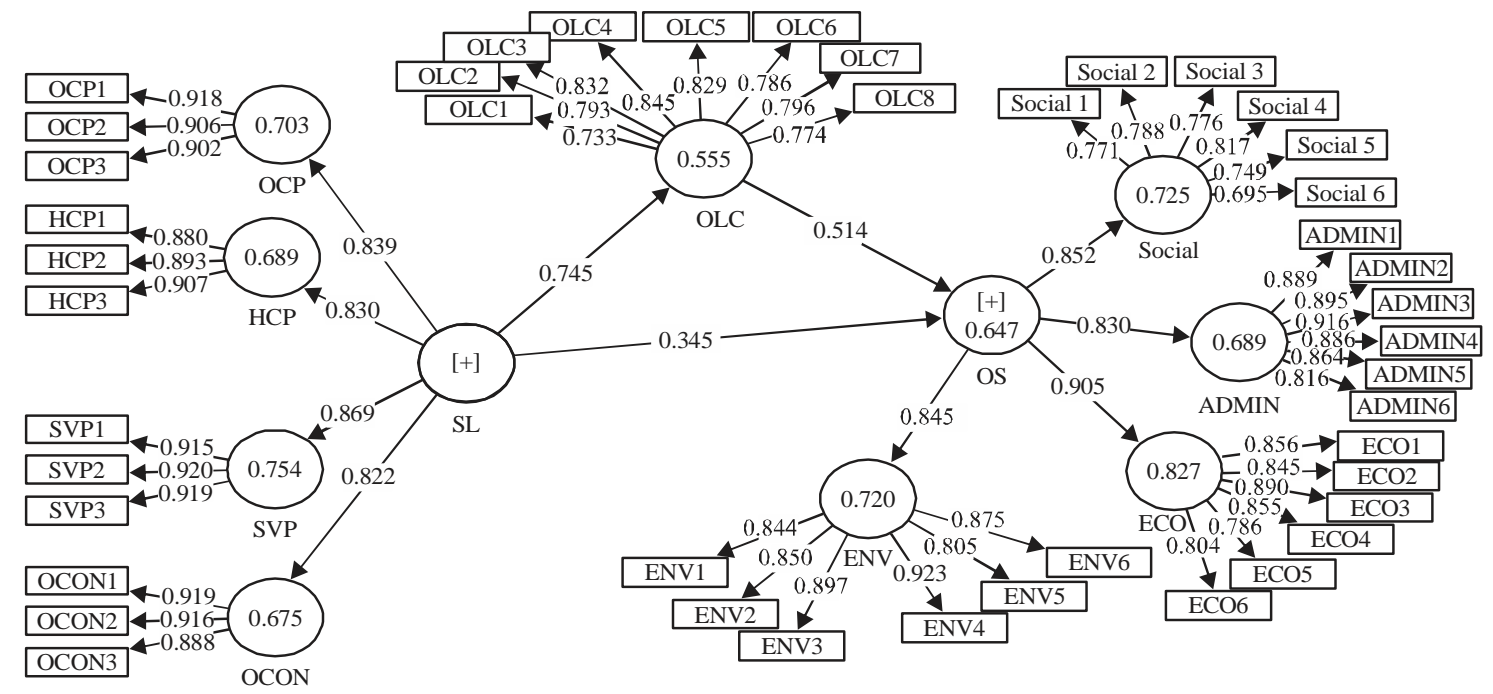

Fig. 2: PLS algorithm results, OCP: Organizational Culture Practices, HCP: Human Capital Practices, SVP: Strategic Vision Practices, OCON: Organizational Control Practices, OLC: Organizational Learning culture, ADMIN: Adminstrative dimension, ECO: Economic dimension, ENV: Ennvironmental dimension, Social: Social dimension, OS: Organizational Sustainablity, SL: Strategic Leadership

Table 4: Results of discriminant validity by Fornell-Larcker criterion

\begin{tabular}{llllllllll}
\hline Variables & ADMIN & ECO & ENV & HCP & OCON & OCP & OLC & SVP & Social \\
\hline ADMIN & $\mathbf{0 . 8 7 8}$ & - & - & - & - & - & - & - & - \\
ECO & 0.641 & $\mathbf{0 . 8 4 0}$ & - & - & - & - & - & - & - \\
ENV & 0.571 & 0.725 & $\mathbf{0 . 8 6 7}$ & - & - & - & - & - & - \\
HCP & 0.545 & 0.568 & 0.530 & $\mathbf{0 . 8 9 3}$ & - & - & - & - & - \\
OCON & 0.602 & 0.542 & 0.457 & 0.535 & $\mathbf{0 . 9 0 8}$ & - & - & - & - \\
OCP & 0.494 & 0.403 & 0.425 & 0.631 & 0.581 & $\mathbf{0 . 9 0 8}$ & - & - & - \\
OLC & 0.683 & 0.668 & 0.636 & 0.679 & 0.579 & 0.586 & $\mathbf{0 . 7 9 9}$ & - & $\mathbf{0 . 9 1 8}$ \\
SVP & 0.658 & 0.526 & 0.519 & 0.630 & 0.649 & 0.615 & 0.658 & $\mathbf{0 . 7 6 7}$ \\
Social & 0.620 & 0.759 & 0.604 & 0.507 & 0.552 & 0.488 & 0.664 & 0.577
\end{tabular}

Diagonals represent the square root of the average variance extracted while the other entries represent the correlations. OCP: Organizational Culture Practices, HCP: Human Capital Practices, SVP: Strategic Vision Practices, OCON: Organizational Control Practices, OLC: Organizational Learning Culture, ADMIN: Adminstrative dimension, ECO: Economic dimension, ENV: Ennvironmental dimension, Social: Social dimension

magnitude of the $\mathrm{f}^{2}$ which is 0.35 (large effects), 0.15 (medium effects) and 0.02 (small effects). The result of $\mathrm{f}^{2}$ as Table 4 shows that one relationship with large effect sizes and two relationships with medium effect sizes.

Further by using the blindfolding procedure this study examined the power of research proposed model regarding the predictive relevance. As recommended by Hair et al. (2017) the blindfolding procedure should use only on the endogenous constructs with a reflective measurement. If the value of $\mathrm{Q}^{2}$ is $>0$ then the predictive relevance of the proposed model exists for a certain endogenous construct (Fornell and Cha, 1994; Hair et al., 2017). As Table 4 shows that all the values of $Q^{2}>0$ indicate that there is an adequate predictive relevance for the proposed model. For the $\mathrm{Q}^{2}$ values, Hair et al. (2017) suggested values of 0.35 (large), 0.15 (medium) and 0.02 (small) as a relative measure of predictive relevance and the result of this study shows that the exogenous have medium predictive relevance.

An issue of the multicollinearity could exist in any study which is not desirable, it means that the variance exogenous constructs explain in the endogenous construct are overlapping with each other and thus, not each explaining unique variance in the endogenous variable (O'Brien, 2007). To measure and assess the degree of multicollinearity, Variance Inflation Factor (VIF) widely used ( $\mathrm{O}$ 'Brien, 2007). There is cause for concern when the largest VIF is >10 (Bowerman, 1990; Myers, 1990). And according to Hair et al. (2017) a multicollinearity issue exists when the largest VIF is $>5$. Table 5 shows multicollinearity diagnostic through VIF which indicates that there is no evidence of significant multicollinearity among the study exogenous constructs because all VIF values are $<5$ ranging from $2.250-1.00$. It means that the variance of exogenous constructs explains in the endogenous construct are not overlapping with each other.

Indirect hypothesis testing (mediation assessment): To test the mediation hypothesis $\mathrm{H}_{4}$, the Preacher and Hayes $(2004,2008)$ method of bootstrapping the indirect effect was applied: 
J. Eng. Applied Sci., 15 (5): 1190-1204, 2020

Table 5: Results of discriminant validity by HTMT

\begin{tabular}{|c|c|c|c|c|c|c|c|c|c|}
\hline Variables & ADMIN & $\mathrm{ECO}$ & ENV & $\mathrm{HCP}$ & $\mathrm{OCON}$ & $\mathrm{OCP}$ & OLC & SVP & Social \\
\hline$\overline{\mathrm{ADMIN}}$ & - & - & - & - & - & - & - & - & - \\
\hline $\mathrm{ECO}$ & 0.690 & - & - & - & - & - & - & - & - \\
\hline ENV & 0.609 & 0.781 & - & - & - & - & - & - & - \\
\hline HCP & 0.597 & 0.632 & 0.584 & - & - & - & - & - & - \\
\hline OCON & 0.658 & 0.599 & 0.501 & 0.598 & - & - & - & - & - \\
\hline OCP & 0.538 & 0.444 & 0.468 & 0.708 & 0.648 & - & - & - & - \\
\hline OLC & 0.733 & 0.727 & 0.686 & 0.757 & 0.638 & 0.645 & - & - & - \\
\hline SVP & 0.711 & 0.576 & 0.564 & 0.705 & 0.719 & 0.682 & 0.721 & - & - \\
\hline Social & 0.689 & 0.855 & 0.671 & 0.575 & 0.631 & 0.555 & 0.743 & 0.652 & - \\
\hline
\end{tabular}

OCP: Organizational Culture Practices, HCP: Human Capital Practices, SVP: Strategic Vision Practices, OCON: Organizational Control Practices, OLC: Organizational Learning Culture, ADMIN: Adminstrative dimension, ECO: Economic dimension, ENV: Ennvironmental dimension, Social: Social dimension

Table 6: Structural path analysis result

\begin{tabular}{|c|c|c|c|c|c|c|c|c|c|c|}
\hline Hypothesis & Relationship & Standard $\beta$ & SE & t-value & $\mathrm{p}$-value & Decision & $\mathrm{R}^{2}$ & $\mathrm{f}^{2}$ & $\mathrm{Q}^{2}$ & VIF \\
\hline$\overline{\mathrm{H}_{1}}$ & SL->OS & 0.345 & 0.344 & 6.906 & 0.000 & Supported & 0.647 & 0.150 & 0.310 & 1.000 \\
\hline $\mathrm{H}_{2}$ & $\mathrm{SL}->\mathrm{OLC}$ & 0.745 & 0.746 & 26.149 & 0.000 & Supported & 0.555 & 1.250 & 0.331 & 2.250 \\
\hline $\mathrm{H}_{3}$ & $\mathrm{OLC}->\mathrm{OS}$ & 0.514 & 0.512 & 11.236 & 0.000 & Supported & 0.647 & 0.332 & 0.310 & 1.000 \\
\hline
\end{tabular}

OLC: Organizational Learning culture, OS: Organizational Sustainablity, SL: Strategic Leadership

Table 7: Bootstrapping the indirect effect of OLC

\begin{tabular}{llccccc}
\hline Hypothesis & Relationship & Standard $\beta$ & SE & t-value & p-value & Decision \\
\hline $\mathrm{H}_{4}$ & SL- $>$ OLC- $>$ OS & 0.383 & 0.382 & 10.451 & 0.000 & Supported \\
\hline Preacher and Hayes & $(2004,2008)$ & OLC: & Organizational Learning & Culture & OS: Organizational Sustainablity SL- Strategic Leadership
\end{tabular}

Preacher and Hayes $(2004,2008)$ OLC: Organizational Learning Culture, OS: Organizational Sustainablity, SL: Strategic Leadership

- $\mathrm{H}_{4}$ : OLC mediates the relationship between SL and OS

The bootstrapping analysis showed that the indirect effect was significant with a $\mathrm{t}$-value of 4.646 and $p$-value $<0.001$. Preacher and Hayes $(2008)$ indicated that when the indirect impact of employee performance on organizational productivity through excellence principles with $95 \%$ Boot CI: $[L L=0.308$, UL $=0.455]$ does not straddle a 0 in between this indicates there is mediation. Thus we can conclude that the mediation effect is statistically significant, indicating that $\mathrm{H}_{4}$ was also supported Table 7.

Importance-Performance Map Analysis (IPMA): This study ran an Importance-Performance Matrix Analysis (IPMA) as a post-hoc procedure in PLS using organizational performance as the outcome construct. The IPMA estimates the total effects represented by the importance of predecessor constructs in shaping the target construct (organizational performance) while their average latent variable scores represent their performance, the computation of the index values (performance scores) was accomplished by rescaling the latent constructs scores to a range of 100 (highest performance) down to 0 (lowest performance) (Hair et al., 2017). According to Ringle and Sarstedt (2016) IPMA enriches the PLS analysis results. Instead of only analyzing the path coefficients (i.e., the importance dimension), it also takes into consideration the average value of the latent constructs and their indicators (i.e., performance dimension). Table 8 shows the findings of importance (total effects) and performance (index values) used for the IPMA.
Table 8: IPMA for OS

\begin{tabular}{lcc}
\hline & $\begin{array}{c}\text { Total effect of the construct } \\
\text { organizational productivity } \\
\text { (Importance) }\end{array}$ & $\begin{array}{l}\text { Index values } \\
\text { (Performance) }\end{array}$ \\
\hline Latent constructs & 0.688 & 60.314 \\
Strategic Leadership (SL) & 0.419 & 58.210 \\
$\begin{array}{l}\text { Organizational Learning } \\
\text { Culture (OLC) }\end{array}$ & & \\
\hline
\end{tabular}

As shown in Fig. 3 this study plotted the total effects scores and index values in a priority map. It can be observed that SL is a very important factor in determining the OS due to its relatively higher importance value compared to other constructs in the proposed model.

Accordingly, the performance of this significant factor (SL) lagged before the OLC. According to Hair et al. (2017). The goal of IPMA is to identify predecessors that have a relatively high importance for the target construct (i.e., those that have a strong total effect) but also a relatively low performance (i.e., low average latent variable scores), the aspects underlying these constructs represent potential areas of improvement that may receive high attention. In sum, in order to increase the OS practices, the managerial activities should focus on enhancing the performance of SL.

Waldman et al. (2006) posit that there is a lack of research on managerial variables directly relevant to CSRactions (Thomas and Simerly, 1995). Bertels suggest that instead of focusing on long-term organizational performance as has largely been the case in prior research investigators should examine managerial tendencies toward using OS values in their decision-making because managers are largely responsible for OS implementation (Hart and Milstein, 1999; Leal Filho et al., 2015; Linnenluecke and Griffiths, 2010; Nidumolu et al., 2009; 


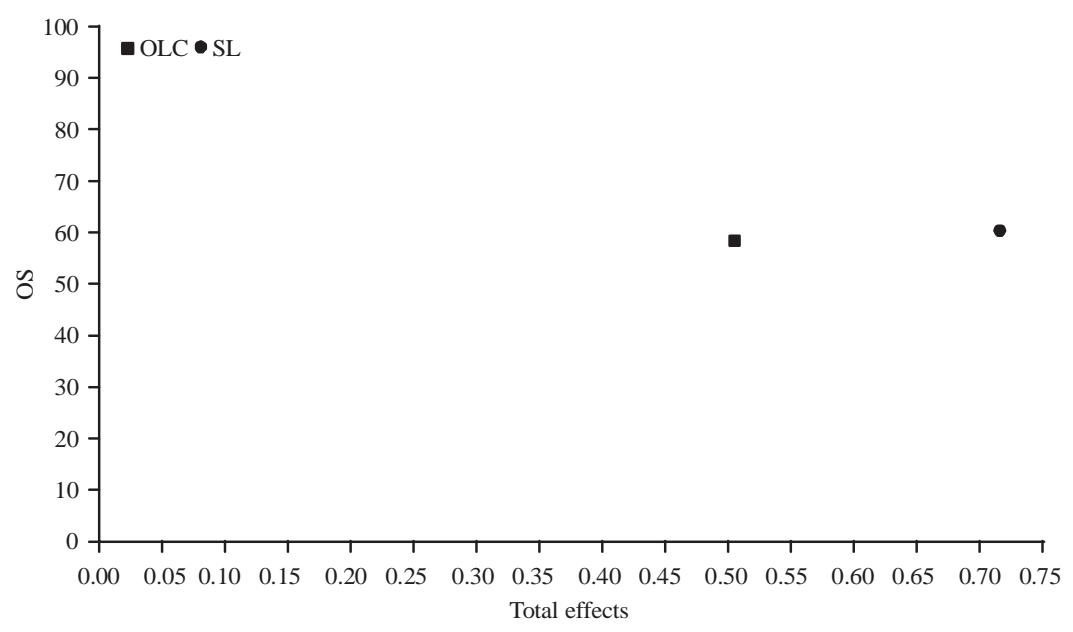

Fig. 3: IPMA (Priority Map) for OS; OLC: Organizational Learning Culture, OS: Organizational Sustainablity, SL: Strategic Leadership; importance performance map

Sajjad and Eweje, 2014; Senge, 2006). Based on Strand (2014) this study suggests that strategic leadership has a significant direct and indirect impact on OS. SL influences OS directly and indirectly through mediating variable of OLC. OS correlates directly with OLC and SL while correlates indirectly with SL. Hence, improved SL will result in better OLC which in turn increase OS activities. The recognition of OLC as mediators in the relationship between SL and OS help the GDRFA's management to develop appropriate strategies to improve SL behaviours within the institutions. Based on the proposed model this study improves the understanding of the role played by SL and OLC in the OS at GDRFA, UAE and highlights relevant implications and suggestions for management and policy makers. The study found that SL positively affect OS among employees within the GDRFAin the United Arab Emirates, this is supported by previous studies (Angus-Leppan et al., 2010; Arevalo and Aravind, 2017; Baumgartner and Rauter, 2017; Chung et al., 2015; Daily et al., 2002; Elenkov et al., 2005; Finkelstein et al., 2009; Leithwood et al., 2004; Morgeson et al., 2013; Orlitzky, 2013; Orlitzky et al., 2011; Rowe, 2001; Rowe et al., 2005; Stogdill, 1974; Strand, 2014; Thomas and Simerly, 1995; Van Marrewijk, 2003). It is explained by the fact that the institutional drivers for OS are thought to come from the national business system and leadership is essential to successful CSR practice (Jones Christensen et al., 2014; Morgeson et al., 2013; Rowe, 2001; Rowe et al., 2005; Waddock and Bodwell, 2017; Waldman and Siegel, 2008). In order to enhance SL, GDRFA's management can create projects and activities to form confidence and trust between the followers. Employees who trust the leader's visionand love their jobs are welling to be engaged on OS activities. Additionally, GDRFA's management should good example the essential organisational standards to help employees to learn and disguise and to have feeling of involvement and accomplishment in the CSR practices. Role modelling at the management level helps to gain respect and trust from the employees. SL is a desirable supervisor behaviour which positively improves employees to participate in OS activities.

Besides focusing on enhancing SL, GDRFA's management should also pay attention to all antecedents of enhancing OLC in order to increase OS. In order to achieve better commitment and engagement, GDRFA's management should help employees to align their objectives to GDRFA's objectives by implementing management by objective strategy. Likewise, it was found that OLC positively affect OS among employees within the GDRFA in the United Arab Emirates this is supported by previous studies (Alexander, 2012; Alexius et al., 2016; Galpin et al., 2015; Klettner et al., 2014; Leal Filho et al., 2015; Mohrman and Worley, 2010; Sajjad and Eweje, 2014; Senge, 2006). Dixon (2017) highlighted the importance of organizational learning, job engagement as a tool to fuel positive emotions and motivations towards the firm. In addition, Lu et al. (2016) show the importance of engaging employees in OS activates and find a suitable job-fit for the employees in order to instil a sense of purpose at work.

The associations among SL and OLC and OS have been investigatedrarely. This study's results provide extra support for these causal relationships, mainly in public sector employees and propose that SL is additional significant factor that directly affects these significant organization outcomes. Similary, the results also revealed that SL has an indirect effect on OS via. OLC among employees within the GDRFA in the United Arab Emirates which confirms the mediation role that OLChas in this context. This concept has significant value for 
researchers interested in OS. Moreover, the variance explained by the proposed model in the current study for OS among employees within the GDRFA in the United Arab Emirates is $64.7 \%$. Thus, GDRFA's managers who want to foster better OLC and OS among employees of the GDRFA should take actions to confirm a more SL (Baumgartner and Rauter, 2017; Orlitzky et al., 2011; Presley et al., 2007; Strand, 2014). It is explained by the fact that SL not only has a normative role by encouraging ethical behavior among followers (Brown et al., 2005; Brown and Trevino, 2014, 2006), it also has a positive impact on in-role performance by strengthening subordinate's relationship with their supervisors and increasing employee's attachment to their organizations. Previous studies showed a positive association between $\mathrm{OS}$ and firm performance (Baumgartner and Rauter, 2017; Eccles et al., 2014; Stead and Stead, 1995; Wiengarten et al., 2017).

\section{CONCLUSION}

The proposed model explained $64.7 \%$ of the variance in OS. Finally, theoretical and managerial implications were discussed.

\section{IMPLICATIONS}

Theoretical contribution for research: We have also addressed Waldman and Siegel (2008) concern at a lack of research around leadership behaviour and OS, finding that an organization implementing OS could be using leadership styles as well as allowing for emergent leaders (Angus-Leppan et al., 2010; Klettner et al., 2014; Morgeson et al., 2013; Orlitzky et al., 2011; Stead and Stead, 1995; Strand, 2014; Wiengarten et al., 2017). This research study has made use of the available literature of the concept of SL and OLC by applying it to the context of GDRFA in the United Arab Emirates to examine its role as a source of SL and its effect on the OS practices. This research can be seen as an attempt to contribute to the understanding of the organizational performance that leads to a firm's enhanced sustainablity and thus, enhanced competitive advantage (Eccles et al., 2014; Rao, 2016; Stead and Stead, 1995; Wiengarten et al., 2017). This concept has significant value for researchers interested in OS. Moreover, the variance explained by the proposed model in the current study for OS among employees within GDRFA in the United Arab Emirates is $64.7 \%$. To the best of the researcher's knowledge, this study is the first study to examine the mediating role of OLC in the relationship between SL and OS. The current study has revealed that OLC partially mediate the relationship between SL and OS. This research offers empirical support to the theoretical relevance of SL and OLC to predict the OS involvement of organization's employees.
Implication for practice: The present research is of significant for practitioners as it illustrates the importance of SL, OS and OLC, although, a link of causality between the variables of this study cannot be clearly recognized because of the cross-sectional design, the results indicate that SL and OLC are vital to increase the employee's involvement on CSR activities. The order of this sequence should encourage organizations to put more emphasis on nurturing supervisor moral person dimension and moral manager one. Moreover, the implications of the key findings provide significant benefits not only for at GDRFA but also to the UAE local government authorities. Incorporating the findings, a number of practical implications were found such as promoting SL behavior as well as OLC which leads to increasing involvement on CSR practices in order to improve the quality of work and the corporate competitive advantages.

It is expected that key findings, especially, the proposed model will help in supporting the UAE government policy initiatives, especially, to increase performance as part of the job at all levels of organizations. The evidence shows a link between OS involvement and better SL and OLC (Baumgartner and Rauter, 2017; Lozano, 2014; Molnar and Mulvihill, 2003; Orlitzky et al., 2011; Presley et al., 2007; Senge, 2006; Smith, 2012; Strand, 2014).

\section{LIMITATIONS}

The first limitation concerns the generalizability of the findings; the targeted sampling of this study includes an employee working in GDRFA in the United Arab Emirates only. Another limitation is that data was gathered by cross-sectional and is not longitudinal in nature. The relationships between variables prescribed in the model of this study are highly case-dependent and thus they vary from organization to another, the model was implemented for an example organization which is GDRF. As described in the introduction section of this research. Moreover, the exclusion of other organizational resources for instance, financial resources represents another limitation of the model. Although, such resources are necessary for organizations in the successful implementation of their capability-building plans, it was decided that taking into account these organizational resources in the model will result in more unnecessary complications to the model and reduce from the main objectives of this research.

\section{REFERENCES}

Abd-Elaziz, M.E., W.M. Aziz, G.S. Khalifa and M. Abdel-Aleem, 2015. Determinants of Electronic Word of Mouth (EWOM) influence on hotel customers purchasing decision. Intl. J. Heritage Tourism Hospitality, 9: 194-223. 
Abou-Shouk, M.A. and G.S. Khalifa, 2017. The influence of website quality dimensions on E-purchasing behaviour and E-loyalty: A comparative study of Egyptian travel agents and hotels. J. Travel Tourism Marketing, 34: 608-623.

Agwa, Y., W. Aziz and G. Khalifa, 2018. Evaluating food and beverage courses in higher private tourism and hotels institutes in Alexandria: Professionals perception. Intl. J. Heritage Tourism Hospitality, 11: 98-110.

Alexander, E.R., 2012. Evaluating Planning: What is Successful Planning and (how) can we Measure it? In: Evaluation for Participation and Sustainability in Planning, Hull, A., E.R. Alexander, A. Khakee, J. Woltjer (Eds.). Routledge, Abingdon, United Kingdom, pp: 41-55.

Alexius, S., S. Furusten and A. Werr, 2016. The 5 as Flies Around Goodies-the Rise of Experts and Services in the Emerging Field of CSR and Sustainability. In: The Organization of the Expert Society, Furusten, S. and A. Werr (Eds.). Routlege, London, UK., ISBN:978-1-138-94795-5, pp: 72-87.

Alharthi, M.N.A.N. and G.S. Khalifa, 2019. Business continuity management and crisis leadership: An approach to Re-Engineer crisis performance within Abu Dhabi Governmental entities. Int. J. Emerging Technol., 10: 32-40.

Alharthi, M.N.A.N., G.S.A. Khalifa, A.E. Abuelhassan, M. Nusari and O. Isaac, 2019. Investigating the impact of leadership and business continuity management on organizational crisis performance. Int. Bus. Manag., 13: 266-278.

Alharthi, M.N.A.N., G.S.A. Khalifa, A.H. Al-Shibami, O. Isaacd and I. Alrajawi, 2019. The impact of strategic leadership on corporate social responsibility: The mediating role of organizational learning culture. Int. Bus. Manage., 13: 331-344.

Alkathiri, M.S., A.E. Abuelhassan, G.S.A. Khalifa, M. Nusari and A. Ameen, 2018. Ethical leadership, affective organizational behaviour and leader-member exchange as predictors for employees performance. J. Eng. Appl. Sci., 14: 6998-7012.

Alsaadi, T.A.R.M., G.S.A. Khalifa, A.E. Abuelhassan, O. Isaac and I. Alrajawi, 2019. Empowering leadership as a predictor for employees creativity: The mediating role of intrinsic motivation. Int. Bus. Manag., 13: 318-330.

Anderson, J.C. and D.W. Gerbing, 1988. Structural equation modeling in practice: $\mathrm{A}$ review and recommended two-step approach. Psychol. Bull., 103: 411-423.

Angus-Leppan, T., L. Metcalf and S. Benn, 2010. Leadership styles and CSR practice: An examination of sensemaking, institutional drivers and CSR leadership. J. Bus. Ethics, 93: 189-213.
Arevalo, J.A. and D. Aravind, 2017. Strategic outcomes in voluntary CSR: Reporting economic and reputational benefits in principles-based initiatives. J. Bus. Ethics, 144: 201-217.

Awang, Z., 2014. Structural Equation Modeling Using AMOS. Universiti Teknologi MARA, Shah Alam, Malaysia,.

Badran, N. and G. Khalifa, 2013. Diversity management: Is it an important issue in Hotel Industry in Egypt?. J. Fac. Tour. Hotel., 7: 275-286.

Barclay, D., C. Higgins and R. Thompson, 1995. The Partial Least Squares (PLS) approach to causal modeling: Personal computer adoption and use as an illustration. Technol. Stud., 2: 285-309.

Baruch, Y. and B.C. Holtom, 2008. Survey response rate levels and trends in organizational research. Hum. Relat., 61: 1139-1160.

Baumgartner, R.J. and R. Rauter, 2017. Strategic perspectives of corporate sustainability management to develop a sustainable organization. J. Clean. Prod., 140: 81-92.

Benn, S., M. Edwards and T. Williams, 2014. Organizational Change for Corporate Sustainability. Routledge, Abingdon, United Kingdom, .

Boal, K.B. and R. Hooijberg, 2000. Strategic leadership research: Moving on. Leadersh. Q., 11: 515-549.

Bowerman, B.L., 1990. Linear Statistical Models: An Applied Approach. 2nd Edn., PWS-Kent Pub. Co, New York, London,.

Brislin, R.W., 1970. Back translation for cross-cultural research. J. Cross-Cultural Psychol., 1: 185-216.

Brown, M.E. and L.K. Trevino, 2006. Ethical leadership: A review and future directions. Leadership Q., 17: $595-616$.

Brown, M.E. and L.K. Trevino, 2014. Do role models matter? An investigation of role modeling as an antecedent of perceived ethical leadership. J. Bus. Ethics, 122: 587-598.

Brown, M.E., L.K. Trevino and D.A. Harrison, 2005. Ethical leadership: A social learning perspective for construct development and testing. Org. Behav. Hum. Decis. Process., 97: 117-134.

Cable, D.M. and D.S. DeRue, 2002. The convergent and discriminant validity of subjective fit perceptions. J. Applied Psychol., 87: 875-884.

Chin, W.W., 1998a. Commentary: Issues and opinion on structural equation modeling. MIS Q., 22: 7-16.

Chin, W.W., 1998b. The Partial Least Squares Approach to Structural Equation Modeling. In: Modern Methods for Business Research, Markoulides, G.A. (Ed.). Lawrence Erlbaum, Mahwah, New Jersey, USA., pp: 295-336.

Chung, K.H., J.E. Yu, M.G. Choi and J.I. Shin, 2015. The effects of CSR on customer satisfaction and loyalty in China: The moderating role of corporate image. J. Econ. Bus. Manage., 3: 542-547. 
Cohen, J., 1988. Statistical Power Analysis for the Behavioral Sciences. 2nd Edn., Lawrence Erlbaum, Hillsdale, New Jersey, USA., ISBN: 0-8058-6283-5, Pages: 128 .

Cook, S.D. and D. Yanow, 1993. Culture and organizational learning. J. Manage. Inq., 2: 373-390.

Daily, C.M., P.P. McDougall, J.G. Covin and D.R. Dalton, 2002. Governance and strategic leadership in entrepreneurial firms. J. Manage., 28: 387-412.

Dingwerth, K. and P. Pattberg, 2009. World politics and organizational fields: The case of transnational sustainability governance. Eur. J. Int. Relat., 15: 707-743.

Dixon, N.M., 2017. The Organizational Learning Cycle: How We Can Learn Collectively. 2nd Edn., Routledge, Abingdon, UK., ISBN:9781317022152, Pages: 264.

Eccles, R.G., I. Ioannou and G. Serafeim, 2014. The impact of corporate sustainability on organizational processes and performance. Manage. Sci., 60: 2835-2857.

Elenkov, D.S., W. Judge and P. Wright, 2005. Strategic leadership and executive innovation influence: An international multi-cluster comparative study. Strategic Manage. J., 26: 665-682.

Finkelstein, S., D.C. Hambrick and A.A. Cannella Jr, 2009. Strategic Leadership: Theory and Research on Executives, Top Management Teams and Boards. Oxford University Press, Oxford, UK., ISBN:978-0-19-516207-3, Pages: 463.

Florea, L., Y.H. Cheung and N.C. Herndon, 2013. For all good reasons: Role of values in organizational sustainability. J. Bus. Ethics, 114: 393-408.

Fornell, C. and D.F. Larcker, 1981. Evaluating structural equation models with unobservable variables and measurement error. J. Market. Res., 18: 39-50.

Fornell, C. and J. Cha, 1994. Partial Least Squares. In: Advanced Methods of Marketing Research, Bagozzi, R.P. (Ed.). Blackwell Publishing Co., Cambridge, pp: 52-78.

Foster, W. and J. Bradach, 2005. Should nonprofits seek profits?. Harvard Bus. Rev., 83: 92-100.

Froehlich, D., M. Segers and P. van den Bossche, 2014. Informal workplace learning in Austrian banks: The influence of learning approach, leadership style and organizational learning culture on managers' learning outcomes. Hum. Resour. Dev. Q., 25: 29-57.

Galpin, T., J.L. Whitttington and G. Bell, 2015. Is your sustainability strategy sustainable? Creating a culture of sustainability. Corporate Governance, 15: 1-17.

Garvin, D.A., 1993. Building a learning organisation. Harvard Bus. Rev., 71: 78-91.

Gauhara, A., 2014. Impact of strategic leadership on knowledge sharing: Case study of Algerian hotels group. Master Thesis, University of Biskra, Biskra, Algeria.
Gefen, D. and E.E. Rigdon, 2011. An update and extension to SEM guidelines for administrative and social science research. MIS. Q., 35: 1-7.

Gefen, D., D.W. Straub and M.C. Boudreau, 2000. Structural equation modeling and regression: Guidelines for research practice. Commun. Assoc. Inform. Syst., 4: 1-77.

Gold, A.H., A. Malhotra and A.H. Segars, 2001. Knowledge management: An organizational capabilities perspective. J. Manage. Inform. Syst., 18: $185-214$.

Hair, Jr., J.F., G.T.M. Hult, C.M. Ringle and M. Sarstedt, 2017. A Primer on Partial Least Squares Structural Equation Modeling (PLS-SEM). 2nd Edn., Sage Publisher, Thousand Oaks, California.

Hair, Jr., J.F., W.C. Black, B.J. Babin and R.E. Anderson, 2010. Multivariate Data Analysis. 7th Edn., Prentice Hall, Upper Saddle River, NJ., ISBN-13: 9780138132637, Pages: 785.

Hart, S.L. and M.B. Milstein, 1999. Global sustainability and the creative destruction of industries. MIT. Sloan Manag. Rev., 41: 23-33.

Henseler, J., C.M. Ringle and M. Sarstedt, 2015. A new criterion for assessing discriminant validity in variance-based structural equation modeling. $\mathrm{J}$. Acad. Marketing Sci., 43: 115-135.

Hung, R.Y.Y., B. Yang, B.Y.H. Lien, G.N. McLean and Y.M. Kuo, 2010. Dynamic capability: Impact of process alignment and organizational learning culture on performance. J. World Bus., 45: 285-294.

Jansen, J.J.P., D. Vera and M. Crossan, 2009. Strategic leadership for exploration and exploitation: The moderating role of environmental dynamism. Leadersh. Q., 20: 5-18.

Jones Christensen, L.I.S.A., A. Mackey and D. Whetten, 2014. Taking responsibility for corporate social responsibility: The role of leaders in creating, implementing, sustaining or avoiding socially responsible firm behaviors. Acad. Manage. Perspect., 28: 164-178.

Joo, B.K. and J.H. Shim, 2010. Psychological empowerment and organizational commitment: The moderating effect of organizational learning culture. Hum. Resour. Dev. Intl., 13: 425-441.

Joo, B.K. and S. Park, 2010. Career satisfaction, organizational commitment and turnover intention: The effects of goal orientation, organizational learning culture and developmental feedback. Leadersh. Organiz. Dev. J., 31: 482-500.

Joo, B.K., 2010. Organizational commitment for knowledge workers: The roles of perceived organizational learning culture, leader-member exchange quality and turnover intention. Hum. Resour. Dev. Q., 21: 69-85. 
Kannan, V.R. and K.C. Tan, 2005. Just in time, total quality management and supply chain management: Understanding their linkages and impact on business performance. Omega, 33: 153-162.

Khalefa, G.S.A., 2015. Ethnic restaurants' meal experience: Egyptian customers' perceptions. Int. J. Heritage Tourism Hospitality, 9: 92-112.

Khalifa, G.S. and E.H.A. Mewad, 2017. Managing drivers and boundaries of Information Technology Risk Management (ITRM) to increase Egyptian hotels market share. Intl. J. Recent Trends Bus. Tourism, 1: 12-31.

Khalifa, G.S.A. and M. Hewedi, 2016. Factors affecting hotel website purchasing intentions: Evidence from Egypt. J. Faculty Tourism Hotels, Fayoum Univ., 8: 50-69.

Khalifa, G.S.A. and N.M. Fawzy, 2017. Measuring E-service quality (Expectation vs. perception) from travel agencies perspective: An empirical study on egyptian hotel websites. Intl. J. Recent Trends Bus. Tourism (IJRTBT), 1: 36-48.

Klettner, A., T. Clarke and M. Boersma, 2014. The governance of corporate sustainability: Empirical insights into the development, leadership and implementation of responsible business strategy. J. Bus. Ethics, 122: 145-165.

Kline, R.B., 2010. Principles and Practice of Structural Equation Modeling. 3rd Edn., The Guilford Press, New York, USA., ISBN-13: 9781606238769, Pages: 427.

Koons, R.C., 2009. Paradoxes of Belief and Strategic Rationality. Cambridge University Press, Cambridge, United Kingdom,

Krejcie, R.V. and D.W. Morgan, 1970. Determining sample size for research activities. Educ. Psychol. Meas., 30: 607-610.

Leal Filho, W., E. Manolas and P. Pace, 2015. The future we want: Key issues on sustainable development in higher education after Rio and the UN decade of education for sustainable development. Int. J. Sustainability Higher Educ., 16: 112-129.

Lee, B.C., J.O. Yoon and I. Lee, 2009. Learners' acceptance of E-learning in South Korea: Theories and results. Comput. Educ., 53: 1320-1329.

Leithwood, K., D. Jantzi, L. Earl, N. Watson, B. Levin and M. Fullan, 2004. Strategic leadership for large-scale reform: The case of England's national literacy and numeracy strategy. Sch. Leadersh. Manage., 24: 57-79.

Linnenluecke, M.K. and A. Griffiths, 2010. Corporate sustainability and organizational culture. J. World Bus., 45: 357-366.

Lozano, R., 2014. Creativity and organizational learning as means to foster sustainability. Sustainable Dev., 22: $205-216$.
Lu, L., A. Lu, D. Gursoy and N. Neale, 2016. Work engagement, job satisfaction and turnover intentions: A comparison between supervisors and line-level employees. Intl. J. Contemp. Hospitality Manage., 28: 737-791.

Mohamed, M.S., G.S.A. Khalifa, A.H. Al-Shibami, I. Alrajawi and O. Isaac, 2019. The mediation effect of innovation on the relationship between creativity and organizational productivity: An empirical study within public sector organizations in the UAE. J. Eng. Appl. Sci., 14: 3234-3242.

Mohamed, M.S., G.S.A. Khalifa, M. Nusari, A. Ameen and A.H. Al-Shibami et al., 2018. Effect of organizational excellence and employee performance on organizational productivity within healthcare sector in the UAE. J. Eng. Appl. Sci., 13: 6199-6210.

Mohamud, S.S., G.S.A. Khalifa, A.E. Abuelhassan and S. Kaliyamoorthy, 2017. Investigating the antecedents of coffee shop customers' behavioral intentions in Kuala Lumpur. Intl. J. Recent Trends Bus. Tourism, 1: 1-14.

Mohrman, S.A. and C.G. Worley, 2010. The organizational sustainability journey: Introduction to the special issue. Organiz. Dyn., 39: 289-294.

Moizer, J. and P. Tracey, 2010. Strategy making in social enterprise: The role of resource allocation and its effects on organizational sustainability. Syst. Res. Behav. Sci., 27: 252-266.

Molnar, E. and P.R. Mulvihill, 2003. Sustainability-focused organizational learning: Recent experiences and new challenges. J. Environ. Plann. Manage., 46: 167-176.

Morgeson, F.P., H. Aguinis, D.A. Waldman and D.S. Siegel, 2013. Extending corporate social responsibility research to the human resource management and organizational behavior domains: A look to the future. Personnel Psychol., 66: 805-824.

Myers, R.H., 1990. Classical and Modern Regression with Applications. 2nd Edn., Duxbury, Washington.

Naqshbandi, M.M. and Y. Kamel, 2017. Intervening role of realized absorptive capacity in organizational culture-open innovation relationship: Evidence from an emerging market. J. General Manage., 42: 5-20.

Nidumolu, R., C.K. Prahalad and M.R. Rangaswami, 2009. Why sustainability is now the key driver of innovation. Harvard Bus. Rev., 87: 56-64.

Nunnally, J.C. and I.H. Bernstein, 1994. Psychometric Theory. 3rd Edn., Tata McGraw-Hill Education, New Delhi, India, ISBN:9780071070881,.

Nusari, M., M. Al Falasi, I. Alrajawy, G.S. Khalifa and O. Isaac, 2018. The impact of project management assets and organizational culture on employee performance. Intl. J. Manage. Hum. Sci., 2: 15-26. 
O'Brien, R.M., 2007. A caution regarding rules of thumb for variance inflation factors. Qual. Quantity, 41: 673-690.

Orlitzky, M., 2013. Corporate social responsibility, noise and stock marketvolatility. Acad. Manage. Perspect., 27: $238-254$.

Orlitzky, M., D.S. Siegel and D.A. Waldman, 2011. Strategic corporate social responsibility and environmental sustainability. Bus. Soc., 50: 6-27.

Paulraj, A., 2011. Understanding the relationships between internal resources and capabilities, sustainable supply management and organizational sustainability. J. Supply Chain Manage., 47: 19-37.

Preacher, K.J. and A.F. Hayes, 2004. SPSS and SAS procedures for estimating indirect effects in simple mediation models. Behav. Res. Meth. Instrum. Comput., 36: 717-731.

Preacher, K.J. and A.F. Hayes, 2008. Asymptotic and resampling strategies for assessing and comparing indirect effects in multiple mediator models. Behav. Res. Methods, 40: 879-891.

Presley, A., L. Meade and J. Sarkis, 2007. A strategic sustainability justification methodology for organizational decisions: A reverse logistics illustration. Int. J. Prod. Res., 45: 4595-4620.

Rao, M.S., 2016. Collaborate to build effective teams to achieve organizational excellence and effectiveness. Ind. Commer. Training, 48: 24-28.

Ribiere, V.M. and A. Sitar, 2003. Critical role of leadership in nurturing a knowledge-supporting culture. Knowledge Manage. Res. Pract., 1: 39-48.

Ringle, C.M. and M. Sarstedt, 2016. Gain more insight from your PLS-SEM results: The importance-performance map analysis. Ind. Manage. Data Syst., 116: 1865-1886.

Ringle, C.M., S. Wende and J.M. Becker, 2015. SmartPLS 3. SmartPLS GmbH, Boenningstedt..

Rowe, W.G., 2001. Creating wealth in organizations: The role of strategic leadership. Acad. Manage. Executive, 15: 81-94.

Rowe, W.G., A.A. Cannella Jr., D. Rankin and D. Gorman, 2005. Leader succession and organizational performance: Integrating the common-sense, ritual scapegoating and vicious-circle succession theories. Leadersh. Q., 16: 197-219.

Sajjad, A. and G. Eweje, 2014. Corporate Social Responsibility in Pakistan: Current Trends and Future Directions. In: Corporate Social Responsibility and Sustainability: Emerging Trends in Developing Economies, Sajjad, A. and G. Eweje (Eds.)., Emerald Group Publishing Limited, Bingley, UK., ISBN: 978-1-78441-152-7, pp: 163-187.

Sanz-Valle, R., J.C. Naranjo-Valencia, D. Jimenez-Jimenez and L. Perez-Caballero, 2011. Linking organizational learning with technical innovation and organizational culture. J. Knowledge Manage., 15: 997-1015.
Schumacker, R.E. and R.G. Lomax, 2004. A Beginner's Guide to Structural Equation Modeling. Vol. 2, Lawrence Erlbaum Associates, New Jersey, USA., ISBN:9780805840186, Pages: 498.

Senge, P.M. and G. Carstedt, 2001. Innovating our way to the next industrial revolution. MIT. Sloan Manage. Rev., 42: 24-38.

Senge, P.M., 2006. Learning for Sustainability. SoL (The Society for Organizational Learning, Incorporated), USA., ISBN: 9780974239026 , Pages: 110.

Skerlavaj, M., M.I. Stemberger and V. Dimovski, 2007. Organizational learning culture-the missing link between business process change and organizational performance. Int. J. Prod. Econ., 106: 346-367.

Skerlavaja, M., J.H. Song and Y. Lee, 2010. Organizational learning culture, innovative culture and innovations in South Korean firms. Exp. Syst. Appli., 37: 6390-6403.

Smith, P.A.C., 2012. The importance of organizational learning for organizational sustainability. Learn. Organiz., 19: 4-10.

Stead, W.E. and J.G. Stead, 1995. An empirical investigation of sustainability strategy implementation in industrial organizations. Res. Corporate Social Perform. Policy, 1: 43-66.

Steurer, R. and M. Hametner, 2013. Objectives and indicators in sustainable development strategies: Similarities and variances across Europe. Sustainable Dev., 21: 224-241.

Stogdill, R.M., 1974. Handbook of Leadership: A Survey of Theory and Research. Free Press, New York, USA., Pages: 613.

Strand, R., 2014. Strategic leadership of corporate sustainability. J. Bus. Ethics, 123: 687-706.

Sullivan, G.M. and R. Feinn, 2012. Using effect size-or why the $\mathrm{P}$ value is not enough. J. Graduate Med. Educ., 4: 279-282.

Tabachnick, B.G. and L.S. Fidell, 2012. Using Multivariate Statistics. 6th Edn., Pearson Education, Boston, MA., ISBN-13: 9780205849574 , Pages: 983.

Templeton, G.F., B.R. Lewis and C.A. Snyder, 2002. Development of a measure for the organizational learning construct. J. Manage. Inform. Syst., 19: $175-218$.

Thomas, A.S. and R.L. Simerly, 1995. Internal Determinants of Corporate Social Performance: The Role of Top Managers. In: Academy of Management Proceedings, Atinc, G. (Ed.). Academy of Management, Briarcliff Manor, New York, pp: 411-415.

Thomas, T.E. and E. Lamm, 2012. Legitimacy and organizational sustainability. J. Bus. Ethics, 110: 191-203. 
Van Houten, D. and G. Jacobs, 2005. The empowerment of marginals: Strategic paradoxes. Disability Soc., 20: 641-654.

Van Marrewijk, M., 2003. Concepts and definitions of CSR and corporate sustainability: Between agency and communion. J. Bus. Ethics, 44: 95-105.

Vera, D. and M. Crossan, 2004. Strategic leadership and organizational learning. Acad. Manage. Rev., 29: $222-240$.

Waddock, S. and C. Bodwell, 2017. Total Responsibility Management: The Manual. Taylor \& Francis, Abingdon, UK., ISBN:9781351280389, Pages: 192.

Waldman, D.A. and D. Siegel, 2008. Defining the socially responsible leader. Leadership Quart., 19: 117-131.
Waldman, D.A., M.S. de Luque, N. Washburn, R.J. House and B. Adetoun et al., 2006. Cultural and leadership predictors of corporate social responsibility values of top management: A GLOBE study of 15 countries. J. Int. Bus. Stud., 37: 823-837.

Werts, C.E., R.L. Linn and K.G. Joreskog, 1974. Intraclass reliability estimates: Testing structural assumptions. Educ. Psychol. Meas., 34: 25-33.

Wiengarten, F., C.K. Lo and J.Y. Lam, 2017. How does sustainability leadership affect firm performance? The choices associated with appointing a chief officer of corporate social responsibility. J. Bus. Ethics, 140: 477-493.

Wikstrom, P.A., 2010. Sustainability and organizational activities-three approaches. Sustainable Dev., 18: 99-107. 